\title{
Efficacy of "Kardiovitin" in integrated treatment in arterial hypertension patients
}

\author{
Elena Katamanova ${ }^{1, *}$, Elena Beygel $^{1}$, Oxana Ushakova $^{1}$, Irina Kudaeva ${ }^{1}$, and Nataliya \\ Pavlenko $^{1}$ \\ ${ }^{1}$ Federal State Budgetary Scientific Institution «East-Siberian Institute of Medical and Ecological \\ Research»12A mikrorayon, build 3, Angarsk, Russia
}

\begin{abstract}
Arterial hypertension is one of the most spread chronic nonspecific human diseases and according to World Health Organization, is due to $30 \%$ of all-death outcomes in general. The aim of this study was to investigate the efficacy of Kardiovitin in the integrated treatment of arterial hypertension. Methods. A total of twenty patients took part in the study seventeen women (average age $-64.5 \pm 8.7$ years, average weight $77.8 \pm 11.4 \mathrm{~kg}$ ) and three men (average age $-54.6 \pm 12.4$ years, average weight $-114 \pm 402 \mathrm{~kg}$ ). A questionnaire, anamnesis, study of risk factors for hypertension, ECG, general blood analysis, general urine analysis, biochemical blood tests, were included in the examination program before and after treatment. Statistical processing was carried out with the program "Statistica 6.0". Differences at $\mathrm{p}<0.05$ were considered statistically significant. Results. It was observed a statistically significant decrease in systolic blood pressure $-120.0(120.0-130.0)$ at $p<0.05$, in total cholesterol - 5.6 (4.6-6.4), LDL cholesterol - $3.2(3.1-3.5)$ at $\mathrm{p}<0.05$ after 2 months Kardiovitin therapy in addition to the standard hypotensive therapy. Conclusion. The results of the study indicate the efficacy of including Kardiovitin in the scheme for basic antihypertensive therapy as a source of bioflavonoids involved in the stabilization of the vascular wall.
\end{abstract}

\section{Introduction}

Arterial hypertension is one of the most spread chronic non-specific human diseases and according to World Health Organization, is due to $30 \%$ of all-death outcomes in general. Available statistical data for Russia indicate that hypertension affects at least $40 \%$ of the population of the Russian Federation, $58 \%$ of women and $37 \%$ of men, and only $48 \%$ of women and $21 \%$ of men regularly take treatment, but the target blood pressure levels reaches in $17.5 \%$ of women and $5.7 \%$ of men [1-3].

Currently, the prevalence of arterial hypertension $(\mathrm{AH})$ is of an epidemic nature, and the $\mathrm{AH}$ can be considered a large-scale non-infectious pandemic. The need to combat $\mathrm{AH}$ is due to the fact that it is one of the leading causes of disability and death. Prolonged increase in blood pressure leads to damage to target organs and the development of cardiovascular complications - heart failure, myocardial infarction, brain stroke cerebral stroke and kidney

\footnotetext{
*Corresponding author: katamanova_e_v@mail.ru
} 
failure [4-6]. The main indicator of treatment effectiveness of AH is the achievement and maintenance of disease control (achievement of the target blood pressure level). Widespread and socio-economic impact of $\mathrm{AH}$ on the society life and each patient necessitates the prevention and timely identification of risk factors, adequate therapy and prophylaxis of complications [7,8].

Dietary Supplement "Kardiovitin" is a natural antioxidant that contains $40 \mathrm{mg}$ of Dihydroquercetin (taxifolin), $120 \mathrm{mg}$ of Acerola plant extract $25 \%$, at least $30 \mathrm{mg}$ of vitamin $\mathrm{C}$, and auxiliary substances in one capsule. It is known that Dihydroquercetin has antioxidant, capillary-protective, hemorheological, antiplatelet and anti-inflammatory activity [9].

Dihydroquercetin is an effective antioxidant agent that interrupts the processes of lipid peroxidation in cell membranes, is able to penetrate into the cytoplasm of the cell and protect the cell from the damaging effects of free radicals, and effectively corrects disorders in various parts of the antioxidant system of the body. Provides a comprehensive antioxidant defense of the body, active prevention of the development of oxidative stress, degenerative-dystrophic processes in tissues and early cellular aging, allows you to effectively counteract the destructive factors of modern ecology, production, diet and lifestyle [10].

Dihydroquercetin has a capillary-protective effect, reduces the permeability and fragility of capillaries, improves microcirculation, helps to inhibit the action of the enzymes hyaluronidase and collagenase, which loosen the connective tissue of the walls of blood vessels and other systems, but activates proline hydroxylase, which promotes the "maturation of the synergistic action of collagen acid - a substrate of proline hydroxylase), thus maintaining strength, elasticity and normalizing the permeability of the vascular wall [11]. Dihydroquercetin, inhibiting free radical processes of lipid peroxidation in biomembranes (breaks the chains of interaction of hydroperoxide and nitroperoxide with lipids and liposaccharides), stabilizes cell membranes, helps to normalize capillary permeability, prevents the development of dystrophic and sclerotic changes in tissues. On the water-lipid surface of the cell membrane, the structure, number and location of hydroxyl groups of the dihydroquercetin molecule with a predominance of hydrophilic groups determine the formation of hydrogen bonds with the polar outer groups of the lipid molecules of the membrane, thereby protecting the membrane from external damage [12].

The membrane-stabilizing effect of dihydroquercetin and its redox properties contribute to the effective functioning of tissue respiration enzymes, oxygen utilization and ATP synthesis in mitochondria. Along with stabilization of erythrocyte membranes and improvement of the oxygen transport function of erythrocytes, these effects determine the antihypoxant, antihemolytic properties of dihydroquercetin, which contribute to an increase in oxygen and energy supply of cells. Dihydroquercetin has a statin-fibrate effect, helping to increase the content in the blood of the so-called good cholesterol - high density lipoproteins, and also reduces the blood triglycerides, "bad" low density lipoproteins, cholesterol. Dihydroquercetin enhances insulin signaling inside the cell. Many of the beneficial effects of dihydroquercetin as a fibrate model suggest the use of the ingredient to prevent dyslipidemia and reduce the risk of cardiovascular disease and its complications in persons with metabolic syndrome. The ability of the dihydroquercetin molecule to modulate the response of intracellular receptors contributes to the utilization of glucose by cells, enhances insulin sensitivity, improves the metabolism of lipids and lipid biomarkers, reduces the possibility of a tendency to gain body weight, and also causes a positive effect on endothelial function, decreases the level of inflammatory reactions and other cardiovascular risk factors [13].

Dihydroquercetin as an addition to therapy with cardiovascular drugs has a favorable effect on the clinical course of hypertension. Decrease in blood pressure, improvement in 
blood microcirculation, reduction of congestion, improvement in patients' well-being (reduction in the frequency of headache, head noise, dizziness, impaired coordination of movement) was noted [14].

The endothelium plays a key role in the control of vascular tone, providing regulation of the vascular lumen depending on the blood flow velocity and blood pressure on the vascular wall, metabolic requirements of the tissue. Therefore, it is extremely important to search for new medications that help restore the endothelium and normalize microcirculation $[15,16]$. These drugs include Kardiovitin, which includes bioflavonoids obtained from Siberian larch wood and vitamin C, both of these components have a stimulating effect on tissue blood flow, stabilizing the barrier function of microvessels, reducing the permeability of the capillary walls and thereby reducing congestion in the microcirculatory bed and restoring the endothelium.

Thus, the aim of this study was to investigate the effectiveness of Kardiovitin in the integrated treatment of arterial hypertension.

\section{Materials and methods}

Seventeen women (average age $-64.5 \pm 8.7$ years, average weight $-77.8 \pm 11.4 \mathrm{~kg}$ ) and three men (average age $-54.6 \pm 12.4$ years, average weight $-114 \pm 402 \mathrm{~kg}$ ) took part in the study. According to the World Health Organization classification, the criteria for stage 2 hypertension were taken as systolic blood pressure of $160 \mathrm{mmHg}$ to $180 \mathrm{mmHg}$ and diastolic blood pressure of $95 \mathrm{mmHg}$ to $104 \mathrm{mmHg}$, the criteria for stage 1 hypertension $140 / 90-159 / 94 \mathrm{mmHg}$. Average experience of the arterial hypertension is 10.0 (5.0-10.0) years.

A questionnaire, anamnesis, study of risk factors for hypertension, ECG, general blood analysis, general urine analysis, biochemical blood tests to determine the levels of fibrinogen, aspartate aminotransferase (AST), alanine aminotransferase (ALT), gammaglutamyl transferase (GGT), creatinine, glomerular filtration rate (GFR), lipid profile, examination by a therapist and cardiologist were included in the examination program before and after treatment. All participants continued to receive the usual standard antihypertensive therapy prescribed by a doctor of a polyclinic or other medical organization.

We used a questionnaire developed by the European Society of Cardiology Working Group on Cardiovascular Pharmacotherapy and the Russian Society of Cardiology (RSO) with the support of SERVIER (https://servier.ru).

Systolic and diastolic blood pressure was measured on the arm using an automatic blood pressure monitor (HD-505, Jawon Medical Co, Kyungsan City, Korea).

Blood pressure was measured in the arm with higher blood pressure in seated position three times with 5 minutes interval. The average value of these three measurements was used in data analysis. Participants did not drink caffeinated beverages such as coffee or tea, and did not workout, smoke, or eat within 2 hours before the blood pressure measurement.

Inclusion criteria were signed informed consent, age from 19 to 65 years, the presence of stage 1 or 2 hypertension. The exclusion criteria were the presence of secondary hypertension; decompensation of cerebrovascular diseases; cardiovascular diseases; malignant tumors; kidney diseases; liver diseases; thyroid diseases; active tuberculosis or other infectious diseases; diabetic patients taking insulin medications; drug or alcohol addiction; taking systemic steroid therapy or immunosuppressive therapy; taking medications that affect blood pressure, such as depressants or Central nervous system stimulants; pregnancy.

ECG was recorded in the supine position with calm breathing using a standard technique on a 12-channel MAC-1200 electrocardiograph (General Electric, USA, 2001). 
The procedure was carried out with maximum comfort for the patient in a calm environment, sufficient lighting and temperature in a special medical office, without distracting and annoying factors such as noise, conversations, and strangers. An electrocardiogram was recorded from three leads from the chest and extremities; recording duration from each lead was three minutes.

In addition, the following vital functions such as body temperature, heart rate (pulse), and frequency of respiratory movements were evaluated. Body temperature measured using a thermometer in the axillary area and as normal values was taken $36.0-36.9^{\circ} \mathrm{C}$. Heart rate (pulse) measured by palpation of the radial artery on the lateral side of the wrist; heart rate 60-80 beats per minute at rest were considered as the normal rate. The frequency of respiratory movements measured by counting the number of movements of the chest and anterior abdominal wall; $16-20$ respiratory movements per minute were as the normal value.

All patients with hypertension included in the study took treatment with "Kardiovitin" for 8 weeks, which is the average time between two medical consultations. Kardiovitin was prescribed 1 capsule 2 times a day for 2 months in the complex of basic therapy for hypertension. Patients took antihypertensive therapy according to the standardized schemes which are included in the first-line drugs with dosages specified in the clinical guidelines. Patients took the following groups of drugs: ACE inhibitors, beta blockers, sartans, drugs containing acetylsalicylic acid (Cardiomagnyl), statins, and hypoglycemic drugs of the biguanide group and sulfonylurea derivatives.

Statistical processing was carried out with the program "Statistica 6.0" (StatSoft, USA, 1999). Differences at $p<0.05$ were considered statistically significant. Research results are presented as values median (Med), upper (Q25), and lower (Q75) quartiles in tables, figures, and text. Comparison of quantitative indicators was performed using the nonparametric Wilcoxon method.

In accordance with the requirements of the Biomedical Ethics Committee, the examination was carried out with the signed informed consent by the patients. The study did not violate the patients' rights and did not endanger their well-being in accordance with the requirements of biomedical ethics approved by the Declaration of Helsinki of the World Medical Association (2000). The conclusion of the Local Ethics Committee No. 31 dated $15 / 02 / 2019$.

\section{Results}

According to the questionnaire data, $30 \%$ of surveyed take statin drugs in addition to the standard therapy for $\mathrm{AH} ; 35 \%$ of examined have type 2 diabetes and take oral hypoglycemic drugs; $10 \%$ of group are smokers; $60 \%$ of the respondents are rarely drinking alcohol, $40 \%$ person drink in 1 or 3 times per month. None of the patients have skipped drugs.

In the group as a whole, an increase in baseline systolic blood pressure above 140 $\mathrm{mmHg}$ and diastolic blood pressure above $90 \mathrm{mmHg}$ with three-time measurements were in 4 patients (20\%) and 1 person (5\%), respectively. Pulse was ranged from 56 to 87 beats per minute and average pulse rate values of group were within the standard values, as well as heart rate. There was a statistically significant decrease in systolic blood pressure after 2 months Kardiovitin therapy (Table 1).

Table 1. Changes in heart rate and blood pressure while receiving Kardiovitin (Median Q25;Q75)

\begin{tabular}{|c|c|c|c|}
\hline Indicators & $\begin{array}{l}\text { Before Kardiovitin } \\
\left.\text { therapy (1 } \mathbf{1}^{\text {st }} \text { visit }\right)\end{array}$ & $\begin{array}{l}\text { After Kardiovitin } \\
\text { therapy }\left(\mathbf{2}^{\text {nd }} \text { visit }\right)\end{array}$ & p value \\
\hline $\begin{array}{c}\text { Systolic blood } \\
\text { pressure }\end{array}$ & $134.5(125.5-142.5)$ & $120.0(120.0-130.0)$ & 0.01 \\
\hline
\end{tabular}




\begin{tabular}{|c|c|c|c|}
\hline Heart rate & $75.0(66.0-80.0)$ & $68.0(62.0-75.0)$ & 0.06 \\
\hline $\begin{array}{c}\text { Diastolic blood } \\
\text { pressure }\end{array}$ & $80.5(80.0-86.0)$ & $80.0(70.0-90.0)$ & 0.6 \\
\hline
\end{tabular}

It is found the following changes via ECG in surveyed patients: sinus bradycardia in $15 \%$ of patients, horizontal and vertical heart axis deviation in $15 \%$ and $5 \%$ of examined, respectively, left heart axis deviation in $5 \%$ patients, and metabolic disorders in $10 \%$ of individuals. It is observed lengthening of the QRS complex (more than 100) in 20\% patients, PQ interval (over 200) in 5\% persons, $R$ wave (more than 100) in $55 \%$ examined, and also exceeding the ratio of RR/PP more than 1.5 was found in $10 \%$ patients. There were no statistically significant changes in ECG after a course of Kardiovitin therapy (Table 2).

Table 2. Changes in ECG while receiving Kardiovitin (Median Q25;Q75)

\begin{tabular}{|c|c|c|c|}
\hline Indicators & $\begin{array}{c}\text { Before Kardiovitin } \\
\text { therapy (1 }\end{array}$ & $\begin{array}{c}\text { st } \mathbf{v i s i t}) \\
\text { After Kardiovitin } \\
\text { therapy (2 }\end{array}$ & $\begin{array}{c}\mathbf{p} \\
\text { visit) }\end{array}$ \\
\hline $\begin{array}{c}\text { Ratue of Cardiac } \\
\text { Contractions }\end{array}$ & $68.0(65.5-76.5)$ & $64.5(62.0-69.5)$ & 0.06 \\
\hline Metabolic disorders & $1.0(1.0-1.0)$ & $1.0(1.0-1.0)$ & 0.47 \\
\hline QRS complex & $97.0(89.5-100.0)$ & $92.0(90.0-99.0)$ & 0.64 \\
\hline QT interval & $416.0(384.0-429.0)$ & $405.0(385.0-417.0)$ & 0.50 \\
\hline QTc interval & $428.5(616.5-440.0)$ & $419.0(410.0-431.0)$ & 0.11 \\
\hline PQ interval & $148.0(136.0-161.0)$ & $151.0(140.0-165.0)$ & 0.82 \\
\hline R wave & $109.0(97.0-117.0)$ & $102.0(98.0-121.0)$ & 1.00 \\
\hline RR interval & $893.5(818.0-965.0)$ & $925.0(856.5-959.0)$ & 0.50 \\
\hline PP interval & $900.0(850.0-1010.0)$ & $920.5(857.0-950.0)$ & 0.11 \\
\hline
\end{tabular}

The General blood test was characterized by normal indicators of red blood (erythrocytes, hemoglobin), normal levels of white blood cells, eosinophilia (more than 5\%) in one woman and an increase in ESR (from $20-27 \mathrm{ml} / \mathrm{min}$ ) in three examined women. It is established statistically significant decrease of eosinophils $3.0(2.0-4.0) \%$ to $2.0(1.0-3.0) \%$ $(\mathrm{p}=0.015)$ and ESR from $10.0(5.5-16.0) \mathrm{mm} / \mathrm{h}$ to $8.0(2.5-10.0) \mathrm{mm} / \mathrm{h}(\mathrm{p}=0.01)$ within Kardiovitin therapy (Table 3). General urine test indicators were normal rate before and after therapy and they had no statistically significant changes.

Table 3. General blood test indicators while receiving Kardiovitin (Median Q25;Q75)

\begin{tabular}{|c|c|c|c|}
\hline Indicators & $\begin{array}{l}\text { Before Kardiovitin } \\
\text { therapy }\left(1^{\text {st }} \text { visit }\right)\end{array}$ & $\begin{array}{l}\text { After Kardiovitin } \\
\text { therapy ( } 2^{\text {nd }} \text { visit) }\end{array}$ & $\begin{array}{r}p \\
\text { value }\end{array}$ \\
\hline Erythrocytes (10x12/L) & $4.75(4.4-5.1)$ & $4.75(4.45-5.0)$ & 0.30 \\
\hline Hemoglobin $(\mathrm{g} / \mathrm{L})$ & $139.5(135.0-146.0)$ & $143.0(135.5-151.5)$ & 0.11 \\
\hline Color indicator (units) & $0.9(0.87-0.93)$ & $0.9(0.88-0.94)$ & 0.60 \\
\hline Platelets $(10 \times 9 / \mathrm{L})$ & $283.0(250.0-329.0)$ & $277.0(252.0-319.0)$ & 0.80 \\
\hline White blood cells (10x9/L) & $6.2(5.3-7.9)$ & $6.8(5.5-8.2)$ & 0.50 \\
\hline $\begin{array}{l}\text { Rod-shaped neutrophils } \\
(\%)\end{array}$ & $3.0(2.0-3.0)$ & $2.0(2.0-3.0)$ & 0.08 \\
\hline $\begin{array}{l}\text { Segmentonuclear } \\
\text { neutrophils (\%) }\end{array}$ & $52.0(47.5-61.0)$ & $54.0(47.0-61.5)$ & 0.80 \\
\hline Eosinophils (\%) & $3.0(2.0-4.0)$ & $2.0(1.0-3.0)$ & 0.015 \\
\hline Basophils (\%) & 0 & 0 & 0.20 \\
\hline Monocytes (\%) & $5.5(5.0-7.0)$ & $6.0(5.0-7.0)$ & 0.20 \\
\hline Lymphocytes (\%) & $33.0(28.0-40.5)$ & $33.5(28.0-42.0)$ & 0.50 \\
\hline $\begin{array}{l}\text { Erythrocyte sedimentation } \\
\text { rate }(\mathrm{mm} / \mathrm{h})\end{array}$ & $10.0(5.5-16.0)$ & $8.0(2.5-10.0)$ & 0.01 \\
\hline Glucose $(\mathrm{mmol} / \mathrm{L})$ & $5.5(5.2-6.2)$ & $5.3(5.1-5.8)$ & 0.06 \\
\hline
\end{tabular}


Before Kardiovitin therapy, blood creatinine level was not exceeded in any of the examined patients, GFR below $60 \mathrm{ml} / \mathrm{min}$ was registered in $29.4 \%$ of women ( 5 people), and GFR was within the standard values in men. AST and ALT levels were normal in examined men. AST level also corresponded to normal range in all surveyed women, but ALT level was above $30 \mathrm{u} / \mathrm{L}$ in two examined women (11.7\%). An increase of GGT (above $61 \mathrm{u} / \mathrm{L})$ was registered in 5 women $(29.4 \%)$ and there was no increase of GGT in men. The fibrinogen level was normal range in all examined patients with hypertension. The blood lipid profile was characterized by an increase in total cholesterol (above $5.2 \mathrm{mmol} / \mathrm{L}$ ) in 14 of 17 women $(82.3 \%)$ and in 3 of 3 men (100\%), normal HDL low LDL cholesterol, low LDL cholesterol in 4 women $(23.5 \%)$ and high LDL cholesterol in 1 man $(33.3 \%)$, increased TG level in 2 of 17 examined women (11.7\%). The atherogenic index was increased in 9 women and 1 man. It is observed statistically significant decrease in total cholesterol and LDL levels in the blood after 2 months Kardiovitin therapy (Table 4).

Table 4. Changes in cholesterol metabolism and fibrinogen indicators while receiving Kardiovitin (Median Q25;Q75)

\begin{tabular}{|c|c|c|c|}
\hline Indicators & $\begin{array}{l}\text { Before Kardiovitin } \\
\left.\text { therapy ( } 1^{\text {st }} \text { visit }\right)\end{array}$ & $\begin{array}{c}\text { After } \\
\text { Kardiovitin therapy } \\
\left(2^{\text {nd }} \text { visit }\right)\end{array}$ & p value \\
\hline $\operatorname{ALT}(\mathrm{u} / \mathrm{L})$ & $19.9(17.7-25.8)$ & $25.0(16.9-30.7)$ & 0.26 \\
\hline $\operatorname{AST}(\mathrm{u} / \mathrm{L})$ & $16.2(15.4-18.7)$ & $16.4(25.3-29.2)$ & 0.5 \\
\hline GGT (u/L) & $22.5(17.8-44.0)$ & $23.2(17.0-37.2)$ & 0.8 \\
\hline $\begin{array}{l}\text { Creatinine } \\
(\mu \mathrm{mol} / \mathrm{L})\end{array}$ & $85.0(78.0-90.0)$ & $81.0(72.0-89.0)$ & 0.5 \\
\hline GFR (ml/min) & $67.1(59.6-72.4)$ & $69.0(65.0-81.0)$ & 0.5 \\
\hline $\begin{array}{l}\text { Total cholesterol } \\
(\mathrm{mmol} / \mathrm{L})\end{array}$ & $6.2(4.9-9.7)$ & $5.6(4.6-6.4)$ & 0.01 \\
\hline $\mathrm{HDL}(\mathrm{mmol} / \mathrm{L})$ & $1.34(1.2-1.6)$ & $1.3(1.0-1.5)$ & 0.2 \\
\hline LDL (mmol/L) & $3.7(3.0-4.4)$ & $3.2(3.1-3.5)$ & 0.03 \\
\hline $\begin{array}{l}\text { Triglycerides } \\
(\mathrm{mmol} / \mathrm{L})\end{array}$ & $1.7(1.0-2.2)$ & $1.6(1.2-2.0)$ & 0.8 \\
\hline Atherogenic index & $4.0(3.6-4.8)$ & $3.4(2.5-5.0)$ & 0.5 \\
\hline Fibrinogen & $2.5(2.1-2.7)$ & $2.8(2.5-3.2)$ & 0.06 \\
\hline
\end{tabular}

\section{Discussion}

More than 800 scientific publications on Dihydroquercetin (Taxifolin) are published in the international database Medline US National Library of Medicine National Institutes of Health (PubMed). In the world, more than 100 studies of various levels have been conducted with this substance, analytical reviews are available, patents are registered and theses have been successfully defended. It has been shown that Dihydroquercetin (Taxifoline) has antioxidant, capillary-protective, hemorheological, antiplatelet and antiinflammatory activity [13-14].

In hypertension, the microcirculation system, which is an important component of maintaining adequate perfusion of organs and tissues, undergoes significant disturbances that are of the greatest clinical importance for the blood circulation of the brain, heart and kidneys. Insufficiency of the microvasculature is formed as a result of a reduction in the number or density of capillaries, both in patients with borderline blood pressure values and in patients with a stable form of hypertension. Another pathological process that occurs in patients with hypertension at the level of microcirculation is significant shifts in the rheological properties of blood. These changes, leading to an increase in blood viscosity, consist in an increase in hematocrit, aggregation of erythrocytes (the rate of spontaneous 
reaction and strength of aggregates) and a decrease in their deformability. Changes in blood rheology, together with a decrease in microvessel density, are responsible for a decrease in tissue perfusion and oxygen transport to tissues, as well as for an increase in peripheral resistance and blood pressure. The course of hypertension is accompanied by a worsening of endothelium-dependent vasodilation, in which the L-arginine - nitric oxide (NO) pathway plays an essential role. Clinical studies of the level of circulating NO metabolites revealed a significant decrease in this indicator in patients with hypertension compared with the control group. Thrombus formation and increased platelet aggregation, as well as a decrease in the level of NO metabolites in platelets are observed in patients with hypertension. This is probably the result of increased transformation of NO to peroxynitrite (ONOO-). It was found that persons with hypertension are in varying degrees of oxidative stress caused by the predominance of the products of free radical lipid oxidation over the total activity of the enzymes of the antioxidant defense of erythrocytes. Aging processes and the development of diseases related to the diseases of "oxidative stress" are associated with oxidative damage: cardiovascular, atherosclerosis, hypertension, cataracts, etc. endothelial function, i.e. his dysfunction develops. The most important role in the development of endothelial dysfunction is attributed to conditions such as dyslipidemia, hyperglycemia, smoking, hypertension. With endothelial dysfunction, firstly, the balance between vasodilating and vasoconstrictor factors is disturbed, and secondly, the endothelial response to external stimuli is perverted; that is, those substances that are normally vasodilators, such as acetylcholine, have a vasoconstrictor effect. Literature data indicate the importance of assessing the state of the endothelium to determine the risk of developing cardiovascular complications in patients with hypertension and atherosclerosis. In this regard, hypertension is considered as a progressive ischemic syndrome with the involvement of macro- and microcirculation, as well as a deterioration in endotheliumdependent vasodilation [5-8].

That is why the full effect of blood pressure control in terms of effective prevention of cardiovascular complications in hypertension is not observed, and new therapeutic approaches are required, including the possibility of influencing microcirculation, endothelial function and reducing the processes of "oxidative stress". As a result of rehabilitation with the use of Kardiovitin, the state of rheological parameters is improved: the blood flow rate through the microvessels increases, which leads to a decrease in the granularity of the erythrocyte flow and a decrease in their aggregation. Areas of focal stasis are usually absent. As a result, the state of hemodynamics improves: the number of functioning capillaries increases, the severity of spasm of arterioles decreases, and the arterio-venular ratio of the diameters of microvessels tends to normalize. Structural changes in microvessels persist, but in some cases there is a tendency to a decrease in the degree of vasodilation of the postcapillary-venular link, the unevenness of their diameter decreases throughout the microvessel, which indicates a weakening of stagnation. The results of the study showed a high clinical efficacy of Kardiovitin, the drug did not affect the parameters of carbohydrate and lipid metabolism, which indicates its metabolic neutrality.

Our post-marketing clinical study, involving 20 people with hypertension, who took 1 capsule of Kardiovitin 2 times a day for 2 months in addition to antihypertensive therapy showed statistically significant decrease in systolic blood pressure, in total cholesterol and LDL levels in the blood after 2 months of Kardiovitin therapy that is completely consistent with the literature data [13-14].

As for the safety of using Kardiovitin, it should be noted that no adverse events were registered during the entire period of treatment. Monitoring of blood pressure, heart rate and duration of the corrected QT interval via ECG in the beginning and after the end of therapy did not reveal any deviations from the initial indicators. 


\section{Conclusion}

Kardiovitin in addition to the standard hypotensive therapy contributes to a statistically significant decrease in systolic blood pressure and also to the normalization of lipid metabolism, with a decrease in total cholesterol and LDL cholesterol.

It is recommended to prescribe 1 capsule of Kardiovitin in the morning and evening during meals for 2 months to improve the efficacy of rehabilitation of patients with arterial hypertension. Kardiovitin therapy should be repeated 3 times a year for 2 months to consolidate the rehabilitation results.

All patients indicated that the drug was well tolerated and improved overall health (decrease or disappearance of shortness of breath, increased activity, improved sleep). The hypotensive effect of Cardiovitin is apparently due to its vasoprotective properties, due to the correction of endothelial dysfunction and NO restoration, and can be widely used in the treatment of hypertensive patients as an addition (but not an alternative) to standard therapy with antihypertensive drugs.

Kardiovitin samples were provided by the company "Sibirskiye tekhnologii".

\section{References}

1. J, Jordan, C, Kurschat, H, Reuter, Arterial Hypertension, Dtsch Arztebl Int. 20, 115(33-34), 557-568 (2018) doi: 10.3238/arztebl.2018.0557

2. L. A. Strizhakov, S. A. Babanov, Arterial hypertension at the workplace: risk factors and the population value, Arkh. 20, 90(9), 138-143 (2018) doi: 10.26442/terarkh2018909138-143

3. K. Dumor, M. Shoemaker-Moyle, R. Nistala, Arterial Stiffness in Hypertension: an Update, Curr Hypertens Rep, 4, 20(8),72 (2018) doi: 10.1007/s11906-018-0867-x

4. R. Mrowka, Arterial hypertension, Acta Physiol (Oxf), 219(4), 697-699 (2017) doi: 10.1111/apha.12855.

5. $2018 \mathrm{ESC} / \mathrm{ESH}$ Guidelines for the management of arterial hypertension. Russian Journal of Cardiology, 23(12), 143-228 (2018) doi: 10.1093/eurheartj/ehy339

6. I. Chazova, Arterial hypertension in the light of current recommendations, Ter Arkh, 20, 90(9), 4-7 (2018) doi: 10.26442/terarkh20189094-7

7. U. O. Wenzel, M. Bode, J. Köhl, H. Am J. Ehmke, A pathogenic role of complement in arterial hypertension and hypertensive end organ damage, Physiol Heart Circ Physiol. 1, 312(3), 349-354 (2017) doi: 10.1152/ajpheart.00759.2016. Epub

8. I. Chazova, Yu. Zhernakova, Diagnosis and treatment of Arterial hypertension [Guidelines]. Sistemnyye gipertenzii, 16(1), 6-31 (2019) doi: 10.26442/2075082X.2019.1.190179

9. R. Patel, B. Mistry Therapeutic potential of quercetin as a cardiovascular agent. Eur J Med Chem, 15, 889-904 (2018) doi: 10.1016/j.ejmech.2018.06.053.

10. K. Manigandan, R. Jayaraj, N. Elangovan, Taxifolin ameliorates 1, 2dimethylhydrazine induced cellproliferation and redox avulsions in mice colon carcinogenesi. Biomedicine \& Preventive Nutrition, 4, 499-509 (2014) http://dx.doi.org/10.1016/j.bionut.2014.08.00 
11. Y. Zhang, J. Yu, X. D. Dong, H. Y. Ji, Molecules, Research on Characteristics, Antioxidant and Antitumor Activities of Dihydroquercetin and Its Complexes, 22, 23(1), 20 (2017) doi: 10.3390/molecules23010020

12. K. Asmi, T. Lakshmi, S. Balusamy, Therapeutic aspects of taxifolin - An update. Journal of Advanced Pharmacy Education \& Research. Published by SPER Publications, 7, 187-189 (2017) https://japer.in/storage/models/article/

13. M. B. Plotnikov, O. I. Aliev, A. V. Sidekhmenova, Dihydroquercetin Improves Microvascularization and Microcirculation in the Brain Cortex of SHR Rats during the Development of Arterial Hypertension, Bull Exp Biol Med, 163(1), 57-60 (2017) doi: 10.1007/s10517-017-3737-7

14. Z. Shu, Y. Yang, L. Yang, Cardioprotective effects of dihydroquercetin against ischemia reperfusion injury by inhibiting oxidative stress and endoplasmic reticulum stress-induced apoptosis via the PI3K/Akt pathway, Food Funct, 22, 10(1), 203-215 (2019) doi: 10.1039 /c8fo01256c

15. D. Konukoglu, H. Uzun, Endothelial Dysfunction and Hypertension, Adv Exp Med Biol, 956, 511-540 (2017) doi: 10.1007/5584_2016_90

16. A. Daiber, S. Steven, A. Weber, Targeting vascular (endothelial) dysfunction, Br J Pharmacol, 174(12), 1591-1619 (2017) doi: 10.1111/bph.13517. Epub 2016 Jul 4. 